\title{
Effect of obesity on the effectiveness of cardiac resynchronization to reduce the risk of first and recurrent ventricular tachyarrhythmia events
}

Barbara Szepietowska*, Bronislava Polonsky, Saadia Sherazi, Yitschak Biton, Valentina Kutyifa, Scott McNitt, Mehmet Aktas, Arthur J. Moss and Wojciech Zareba

\begin{abstract}
Background: Obesity is associated with multiple adverse cardiovascular conditions and may increase the risk of ventricular tachyarrhythmias (VTNF). There is limited data on the association between obesity and risk of VTNF requiring appropriate implantable cardioverter-defibrillator (ICD) therapies and the effectiveness of cardiac resynchronization therapy (CRT) to reduce risk for VTNF. The multicenter automatic defibrillator implantation trial with cardiac resynchronization therapy (MADIT-CRT) was design to investigate effectiveness of CRT therapy to reduce cardiovascular outcome for patients with heart failure (HF) and reduced ejection fraction.

Methods and results: We identified patients enrolled in the MADIT CRT trial as obese $(n=433)$ and non-obese $(n=845)$ and analyzed their risk for appropriate device therapy for VTNF, repeated VTNF events, fast VTNF, as well as events after first VTNF episodes. Obesity was defined as body mass index (BMI) $\geq 30 \mathrm{~kg} / \mathrm{m}^{2}$. Among ICD patients, the risk of first appropriate ICD therapy for VTNF at 3 years was similar between obese and non-obese patients (23 vs. $21 \%, p=0.76)$. CRT-D treatment reduced the risk of first appropriate ICD therapy both in non-obese ([HR]; 0.58 [CI]: 0.42-0.79; $p<0.001$ ) and obese patients ( $\mathrm{HR} 0.75,95 \% \mathrm{Cl} 0.5-1.38 ; \mathrm{p}=0.179$ ) (interaction $\mathrm{p}$ value 0.323). Similarly, a significant reduction in the risk of fast VTNF was observed in non-obese patients ([HR]; $0.49[\mathrm{Cl}]: 0.33-0.73 ; \mathrm{p}<0.001)$ and obese ([HR]; 0.49 [Cl]: 0.29-0.81; p < 0.01), (interaction p value 0.984).
\end{abstract}

Conclusion: Obese and non-obese patients with mild heart failure have a similar risk of ventricular tachyarrhythmias. Obesity in mild heart failure did not diminish the clinical benefit of cardiac resynchronization therapy to reduce risk for appropriate ICD therapy.

Clinical trial registration http://clinicaltrials.gov/ct2/show/NCT00180271

Keywords: Obesity, Cardiac resynchronization therapy, Implantable cardioverter defibrillator, Heart failure, Ventricular tachyarrhythmias

\section{Background}

Obesity contributes to the development of several risk factors that are associated with cardiac arrhythmias, including metabolic syndrome, ischemic heart disease [1,

\footnotetext{
*Correspondence: barbara_szepietowska@URMC.Rochester.edu Heart Research Follow-up Program, Cardiology Division, University of Rochester Medical Center, 265 Crittenden Blvd., PO Box 653, Rochester, NY 14642, USA
}

2], atrial enlargement, left ventricular hypertrophy [3], systolic and diastolic heart failure $[4,5]$ and sleep apnea [6]. The cardiac structural abnormalities that are associated with obesity may potentially increase the risk for ventricular arrhythmogenesis including myocyte hypertrophy, fibrosis, focal myocardial disarray, fatty infiltration and increased epicardial fat [7]. Patients with obesity have also been shown to have disrupted pattern of gap junction protein expression and distribution. [8] Obesity 
is also associated with delayed ventricular repolarization as evidenced by prolongation of QT/QTc interval $[8,9]$. Additional mechanism responsible for increased risk for arrhythmias is sympathetic over activation present in patients with obesity [10]. These changes in part may contribute to the increased propensity to VT/VF in obese individuals [11].

The association between atrial fibrillation and obesity has been thoroughly investigated [12-16], however the association between ventricular arrhythmias and obesity is not fully understood. Increased prevalence for cardiac tachyarrhythmias and increased risk of sudden cardiac death was reported in obese post myocardial infarction patients with abnormal ejection fraction [17-19].

In our previous MADIT II, where ICD therapy was tested for prevention for sudden cardiac death, we observed that obesity is an independent risk factor for VT/VF [17]. The aim of the current study was to: (i) evaluate the association between obesity and the risk of appropriate implantable cardioverter-defibrillator (ICD) therapy delivered for VT/VF in patients with mild heart failure and reduced ejection fraction; (ii) evaluate the effectiveness of cardiac resynchronization therapies to reduce risk for VT/VF in obese and non-obese patients, (iii) to assess the prognostic implications of first VT/VF on the subsequent tachyarrhythmia event and all-cause mortality in this population.

\section{Methods}

\section{Study population}

The results and the protocol of the Multicenter Automatic Defibrillator Implantation Trial with Cardiac Resynchronization Therapy (MADIT-CRT) trial have been previously reported [20]. From December 22nd, 2004, through June 24th, 2009 a total of 1820 patients were enrolled at 110 centers in US, Canada and in Europe. Patients of either sex who were at least 21 years old, with ischemic cardiomyopathy (NYHA class I or II) or non-ischemic cardiomyopathy (NYHA class II only), sinus rhythm, a left ventricular ejection fraction (LVEF) of $30 \%$ or less and prolonged intraventricular conduction (QRS duration $\geq 130 \mathrm{~ms}$ ) were randomly assigned in 3:2 ratio to CRT-D or ICD only. Patients had an ambulatory follow-up one-month after the device implantation, and every 3 months thereafter until the termination of the trial. The mean follow-up of the enrolled patients was 40 months. All patients had clinical evaluation at each follow up visit or at any meaningful clinical event.

Following the primary publication of MADIT-CRT, subsequent analyses showed that the benefit of CRT-D in the trial was restricted to patients with left bundle branch block (LBBB) [21]. Patients with obesity were defined as $\mathrm{BMI} \geq 30 \mathrm{~kg} / \mathrm{m}^{2}$ at the baseline visit [22].

\section{Device programming and Interrogation}

Commercially available transvenous devices from Boston Scientific and standard techniques were used in the MADIT-CRT. Devices were programmed according to the study protocol [23] to monitor therapy, with a protocol recommendation to a setting of the VT zone at 180 beats/min (bpm) and the VF zone at $210 \mathrm{bpm}$. Sensitivity was programmed according to physician discretion. Detection times were $2.5 \mathrm{~s}$ for the VT zone and $1.0 \mathrm{~s}$ for the VF zone. The protocol recommended programming the VT zone with first therapy to burst-type antitachycardia pacing with 8 pulses at $88 \%$ of the measured cycle length with a 10-milliseconds decrement between bursts, then shock therapy; second therapy was recommended to be shock at the defibrillation threshold plus at least $10 \mathrm{~J}$ (if possible). The remaining therapies were to be maximal energy shocks. All shocks were biphasic. The ICDs were interrogated quarterly, after which ICD data and disks were sent to the core laboratory for categorization and final adjudication of detected arrhythmias. Arrhythmia episode was defined as any type of therapy rendered including antitachycardia pacing and shock. The adjudication committee adjudicated the episode. VT was defined as the ventricular rate up to $250 \mathrm{bpm}$; VF was defined as ventricular rate faster than $250 \mathrm{bpm}$ with disorganized ventricular electrographs. Only appropriate ICD therapy delivered for VT ( $\geq 180 \mathrm{bpm})$ or VF was considered in the present study.

\section{End points definition}

The end point of the current study was first VT/VF requiring appropriate ICD therapy, repeated VT/VF requiring appropriate ICD therapy, VT/VF or death whichever came first, fast VT/VF defined as $>200 \mathrm{bpm}$ and VT/VF requiring ICD shocks.

\section{Statistical analysis}

Baseline clinical characteristics were compared using the nonparametric Kruskal-Wallis test for continuous variables and the Chi square-test or Fisher's exact test for dichotomous variables, as appropriate. We performed Kaplan-Meier survival analyses of unadjusted cumulative event rates stratified by obesity with the log-rank test for determination of statistical significance.

The Cox proportional hazards multivariate regression model was used to estimate hazard ratios for risk 
of appropriate ICD therapy delivered for (VT/VF), VT/ $\mathrm{VF} /$ death, VT/VF greater than $200 \mathrm{bpm}$ and shock delivered for VT/VF. These hazard ratios were estimated for two separate groups: non-obese and obese patients. The independent variables were chosen using the best subsets selection method and adjustment included: assigned treatment, race (Black/African American), age at enrollment, creatinine $\geq 1.4$, female, left ventricle end diastolic volume index, myocardial infarction prior to enrollment, enrollment NYHA classification, prior hospitalization during preceding year, QRS $<150 \mathrm{~ms}$, ventricular arrhythmias requiring treatment prior to enrolment. The full multivariable model is presented in Additional file 1: Table S1. We followed this statistical methodology because we wanted to develop a parsimonious model which excluded variables which were not significantly predictive of the endpoints and would have very little impact on the results. In this way we attempted to maximize statistical power, an important consideration in subgroup analysis. To assess the CRT-D treatment differences between patients by obesity, a treatment-by-obesity medication interaction term was included in the Cox proportional hazard regression models. A two degree of freedom Wald test was done to assess the strength of the interaction between the groups and CRT-D treatment. All statistical tests were two-sided and a p $<0.05$ was considered statistically significant, because of the numerous statistical tests, the $\mathrm{p}$ value reported should be considered as nominal and not corrected for multiple comparison. Analyses were carried out with SAS software (version 9.3, SAS institute, Cary, North Carolina).

\section{Results}

MADIT CRT in total included 1820, 539 were excluded due to non-LBBB and 17 due to not having BMI at baseline. The study population consisted of 1264 patients with LBBB including 833 (66 \%) non-obese and 431 (34\%) obese patients. Clinical and demographic characteristics of the study population are presented in Table 1 . In summary, obese patients were younger by about 5 years, more often presented with diabetes and hypertension, and had longer QRS duration, higher resting heart rate, systolic and diastolic blood pressure, higher glomerular filtration rate (GFR) and lower plasma brain natriuretic peptide (BNP) () levels. Patients with obesity more often reported usage of diuretics including aldosterone receptor antagonists. ICD programming was also not different between non-obese and obese. A total of 266 (21\%) LBBB patients experienced at least one tachyarrhythmia event at a heart rate $\geq 180$ beats $/ \mathrm{min}$.
Table 1 Clinical characteristics of LBBB patients by obesity in MADIT-CRT

$$
\text { Non-obese } n=833 \text { Obese } n=431 \quad p \text { value }
$$

\begin{tabular}{|c|c|c|c|}
\hline \multicolumn{4}{|l|}{ Demographics } \\
\hline Age, mean $\pm S D, y$ & $65.8 \pm 10.6$ & $61.1 \pm 10.6$ & $<0.001$ \\
\hline Women, n (\%) & $263(32)$ & $125(29)$ & 0.348 \\
\hline White $n(\%)$ & $764(92)$ & $389(90)$ & 0.272 \\
\hline \multicolumn{4}{|l|}{ Cardiac history n (\%) } \\
\hline $\begin{array}{l}\text { CRT-D assigned } \\
\mathrm{n}(\%)\end{array}$ & $498(60)$ & $259(60)$ & 0.915 \\
\hline $\begin{array}{l}\text { Ischemic cardiomyo- } \\
\text { pathy }\end{array}$ & $374(45)$ & $183(42)$ & 0.408 \\
\hline Diabetes & $216(26)$ & $166(39)$ & $<0.001$ \\
\hline Hypertension & $497(60)$ & $300(70)$ & $<0.001$ \\
\hline Prior Ml & $268(33)$ & $135(32)$ & 0.761 \\
\hline Prior CABG & $191(23)$ & $90(21)$ & 0.401 \\
\hline $\begin{array}{l}\text { Prior HF hospitaliza- } \\
\text { tion }\end{array}$ & $310(38)$ & $172(40)$ & 0.421 \\
\hline $\begin{array}{l}\text { Past atrial arrhyth- } \\
\text { mias }\end{array}$ & $93(11)$ & $47(11)$ & 0.892 \\
\hline $\begin{array}{l}\text { Past ventricular } \\
\text { arrhythmias }\end{array}$ & $47(6)$ & $34(8)$ & 0.121 \\
\hline \multicolumn{4}{|c|}{ Clinical characteristics at enrolment mean \pm SD } \\
\hline LVEF (\%) & $28.9 \pm 3.5$ & $28.5 \pm 3.4$ & 0.132 \\
\hline QRS duration (ms) & $162.1 \pm 19.3$ & $164.7 \pm 19.0$ & 0.012 \\
\hline $\begin{array}{l}\text { Resting heart rate } \\
(\mathrm{bpm})\end{array}$ & $67.7 \pm 10.9$ & $69.2 \pm 10.9$ & 0.019 \\
\hline $\begin{array}{l}\text { Systolic blood pres- } \\
\text { sure }(\mathrm{mmHg})\end{array}$ & $122.2 \pm 17.2$ & $123.6 \pm 17.0$ & 0.090 \\
\hline $\begin{array}{l}\text { Diastolic blood pres- } \\
\text { sure }(\mathrm{mmHg})\end{array}$ & $70.7 \pm 9.9$ & $72.9 \pm 10.7$ & 0.002 \\
\hline $\begin{array}{r}\text { Brain natriuretic } \\
\text { peptide pg/dl }\end{array}$ & $134.8 \pm 168.9$ & $78.7 \pm 91.9$ & $<0.001$ \\
\hline $\begin{array}{l}\text { Glomerular filtration } \\
\text { rate } \mathrm{ml} / \mathrm{m}^{2}\end{array}$ & $68.5 \pm 19.8$ & $70.8 \pm 20.4$ & 0.046 \\
\hline \multicolumn{4}{|l|}{ Medications, n (\%) } \\
\hline $\begin{array}{l}\text { ACE inhibitor or } \\
\text { aldosterone recep- } \\
\text { tor antagonists }\end{array}$ & $797(96)$ & $418(97)$ & 0.254 \\
\hline $\begin{array}{l}\text { Aldosterone recep- } \\
\text { tor antagonists }\end{array}$ & $254(30)$ & $172(40)$ & $<0.001$ \\
\hline Aspirin & $500(60)$ & $275(64)$ & 0.191 \\
\hline Beta-blockers & $779(94)$ & 408 (95) & 0.419 \\
\hline Diuretic & $536(64)$ & $328(76)$ & $<0.001$ \\
\hline Statins & $522(63)$ & $281(65)$ & 0.375 \\
\hline \multicolumn{4}{|l|}{ ICD programming } \\
\hline $\begin{array}{l}\text { Rate of lowest } \\
V T<180 \mathrm{bpm}\end{array}$ & $153(20)$ & $63(16)$ & 0.060 \\
\hline $\begin{array}{l}\text { Rate of highest } \\
V F>210 \text { bpm }\end{array}$ & $79(10)$ & $45(10)$ & 0.650 \\
\hline ATP $(\%)$ & $743(91)$ & $399(93)$ & 0.267 \\
\hline $\begin{array}{l}\text { Cut-off rate of lowest } \\
\text { VT zone (ms) }\end{array}$ & $177 \pm 7$ & $178 \pm 7$ & 0.029 \\
\hline $\begin{array}{l}\text { Cut-off rate of VF } \\
\text { zone (ms) }\end{array}$ & $209 \pm 9$ & $210 \pm 8$ & 0.357 \\
\hline
\end{tabular}




\section{The appropriate ICD therapies in obese and non-obese patients}

Among patients in the ICD arm only, the risk for appropriate ICD therapy at 3 years was similar between obese and non-obese patients for $\mathrm{VT} / \mathrm{VF}, \mathrm{VF} / \mathrm{VF} /$ death, as well as shock delivered for VT/VF, and VT/VF higher than 200 (Fig. 1). Multivariable analysis consistently showed that risk for appropriate therapy in ICD arm was similar for non-obese and obese patients (Table 2).

In our population non-obese and obese presented with similar rate for appropriate therapy in ICD arm, CRT-D arm and both arm combined (Table 3) and (Additional file 2: Figure S1).

\section{The effect of CRT-D on the risk of appropriate implantable cardioverter-defibrillator therapy}

Kaplan-Meier survival analysis showed the cumulative probability of the of first appropriate ICD therapies delivered for VT/VF was significantly decreased for nonobese patients obese did not demonstrate a decreased when CRT-D was compared to ICD group only (Fig. 2).

However, multivariable analysis showed that CRT-D treatment significantly reduced the risk of appropriate ICD therapy in non-obese patients ([HR]; 0.58 [CI]: $0.42-$ $0.79 ; \mathrm{p}<0.001)$ and to a lesser degree in obese patients
Table 2 Risk of appropriate implantable cardioverterdefibrillator therapy in obese versus non-obese patients in ICD arm

\begin{tabular}{lll}
\hline & Number events & $\begin{array}{l}\text { Adjusted HR }(\mathbf{9 5} \% \mathbf{C l}) \\
\text { p value }\end{array}$ \\
\hline VTNF & 124 & 1.33 \\
& & $(0.91-1.96)$ \\
& & 0.144 \\
VTNF/death & 159 & 1.25 \\
& & $(0.89-1.75)$ \\
& & 0.199 \\
VTNF greater than & 62 & 0.96 \\
200 bpm & & $(0.57-1.64)$ \\
& & 0.880 \\
Shock delivered for VTNF & 76 & 0.96 \\
& & $(0.67-1.79)$ \\
& & 0.745
\end{tabular}

After adjustment for: race (Black/African American), age at enrollment creatinine $\geq 1.4$, female sex, left ventricle end diastolic volume index, myocardial infarction prior to enrollment, enrollment NYHA classification, prior hospitalization during prior year, $\mathrm{QRS}<150$, ventricular arrhythmias requiring treatment prior to enrolment

(HR 0.75, $95 \%$ CI 0.5-1.38; $\mathrm{p}=0.179)$, however interaction $p$ value was not significant $p=0.323$. Significant reduction in risk of fast $\mathrm{VT} / \mathrm{VF}$ was observed in

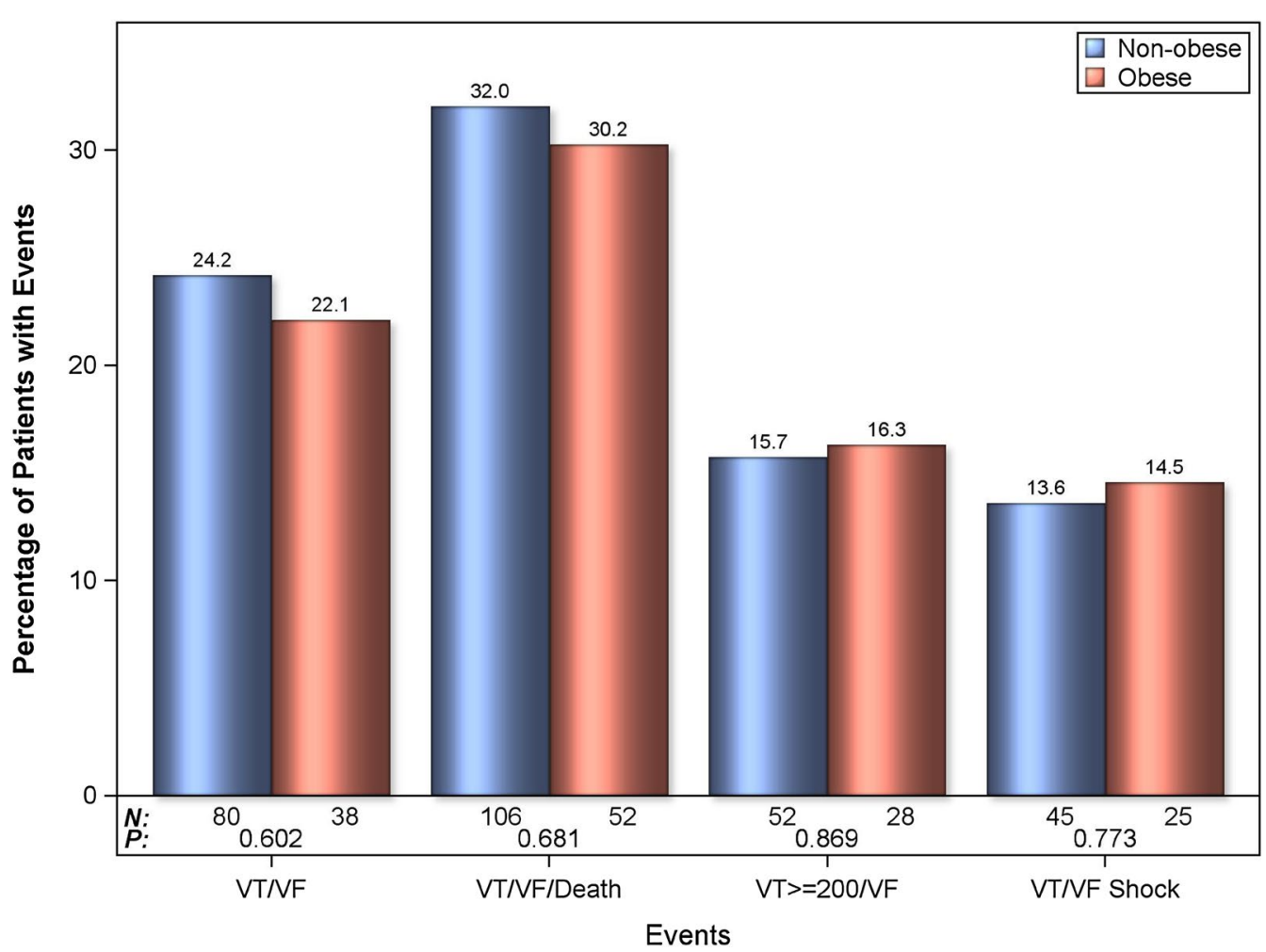

Fig. 1 Percentage of patients with appropriate ICD therapy for VT/NF at 3 years in non-obese and obese in ICD arm 
Table 3 Rates of recurrent appropriate ICD therapies for VT/VF per 100 patient-years at risk assessed at a 3-year follow-up

\begin{tabular}{|c|c|c|c|c|}
\hline Treatment arm & Events & Non-obese & Obese & $p$ value \\
\hline \multirow[t]{4}{*}{$I C D$} & VTNF & 56.82 & 44.58 & 0.244 \\
\hline & VT/NF/Death & 61.3 & 48.44 & 0.237 \\
\hline & $\begin{array}{l}\text { VT/NF greater than } \\
200 \mathrm{bpm}\end{array}$ & 23.94 & 19.29 & 0.384 \\
\hline & $\begin{array}{l}\text { Shock delivered for } \\
\text { VT/NF }\end{array}$ & 22.71 & 18.43 & 0.522 \\
\hline \multirow[t]{4}{*}{ CRT-D } & VTNF & 27.97 & 40.22 & 0.453 \\
\hline & VTNF/death & 30.95 & 42.85 & 0.359 \\
\hline & $\begin{array}{l}\text { VTNF greater than } \\
200 \text { bpm }\end{array}$ & 9.25 & 7.49 & 0.495 \\
\hline & $\begin{array}{l}\text { Shock delivered for } \\
\text { VTNF }\end{array}$ & 8.72 & 5.41 & 0.171 \\
\hline
\end{tabular}

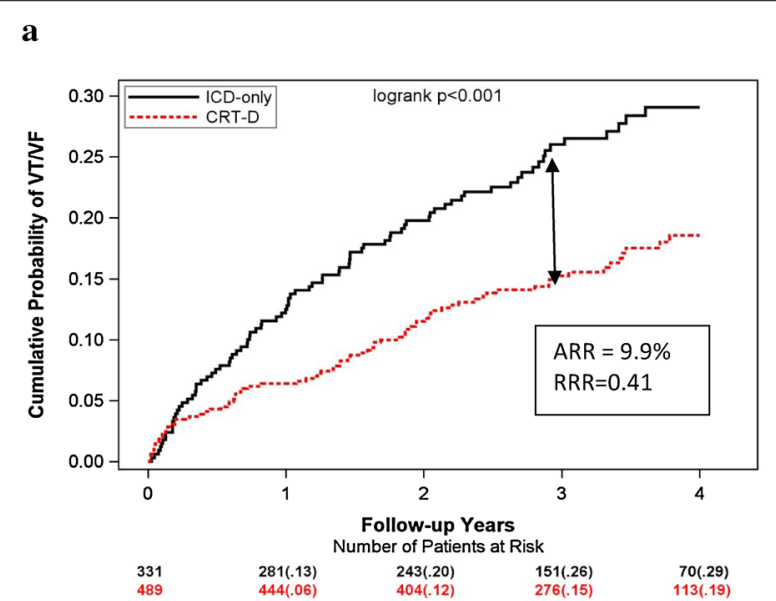

b

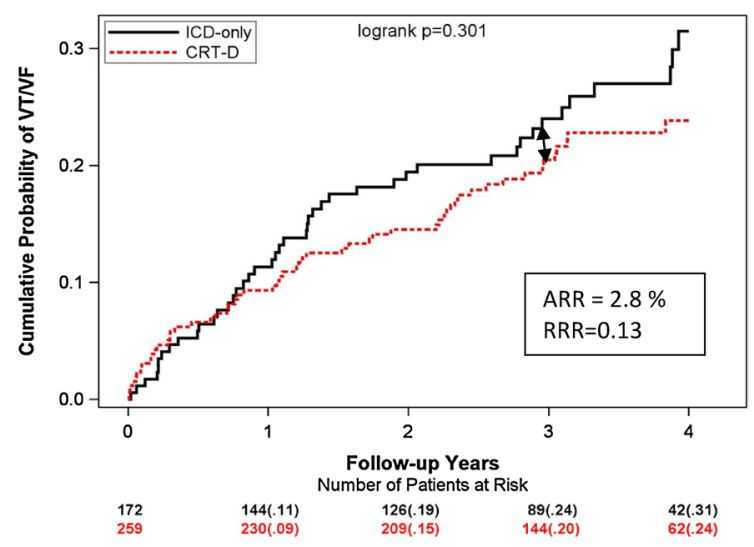

Fig. 2 Cumulative probability of VT/VF by treatment arm in: a nonobese and $\mathbf{b}$ obese patients non-obese ([HR]; $0.49[\mathrm{CI}]: 0.33-0.73 ; \mathrm{p}<0.001)$ and obese patients $([\mathrm{HR}] ; 0.49[\mathrm{CI}]: 0.29-0.81 ; \mathrm{p}<0.01)$ (Fig. 3).

\section{The effect of CRT-D on the risk of recurrent appropriate} implantable cardioverter-defibrillator therapy and death Among patients who experienced a first incidence of VT/ VF, Kaplan-Meier survival analysis showed no statistically significant difference between treatment groups by obesity status with regards to the occurrence of a second VT/VF (Fig. 4). Consistently, multivariable model showed that the benefit of CRT to reduce the VT/VF end point was not evident in non-obese and obese patients among those who experienced a first event (Table 4). CRT-D therapy was effective in reducing VT/VF faster than $200 \mathrm{bpm}(\mathrm{p}=0.086)$ and VT/VF episodes requiring ICD shocks $(\mathrm{p}=0.031)$ in obese patients only.

Among non-obese patients who had an appropriate ICD therapy a higher risk of death was observed ([HR]; $2.02[\mathrm{CI}]: 1.14-3.57 ; \mathrm{p}=0.014)$, similarly to obese patients ([HR]; $2.79[\mathrm{CI}]: 1.37-5.68 ; \mathrm{p}=004$ ) (Table 4) comparing to those who did not have appropriate ICD therapy.

\section{Discussion}

To our knowledge, the present study is the first to assess the effect of obesity on the risk of VT/VF and recurrent VT/VF in response to CRT-D treatment. In our current analysis obesity was not associated with a higher risk of first and subsequent ventricular tachyarrhythmias and did not diminish clinical benefit of cardiac resynchronization therapy to reduce risk for appropriate therapy delivered for VT/VF. Consistently both non-obese and obese patients showed higher risk for death after the occurrence of the appropriate ICD therapy.

Our previous MADIT II study reported a higher rate of VT/VF in obese post-infarction patients [17]. MADIT II was a post-infarction population study without a requirement of heart failure. The overall rate for VT/VF was $10 \%$ higher than in MADIT-CRT. The MADIT CRT population consisted of patients with both ischemic and non-ischemic cardiomyopathy [24]. Additionally, pharmacological treatment and prevention strategies for heart failure optimize over the years and this may contribute to lower rate for VT/VF in current population [25]. Success strategies for ICD implantation are also similar in obese and non-obese [26]. CRT-D reduces the risk for heart failure, death and VT/VF $[20,27,28]$, but significant evidence suggests that the benefit derived from CRT varies 


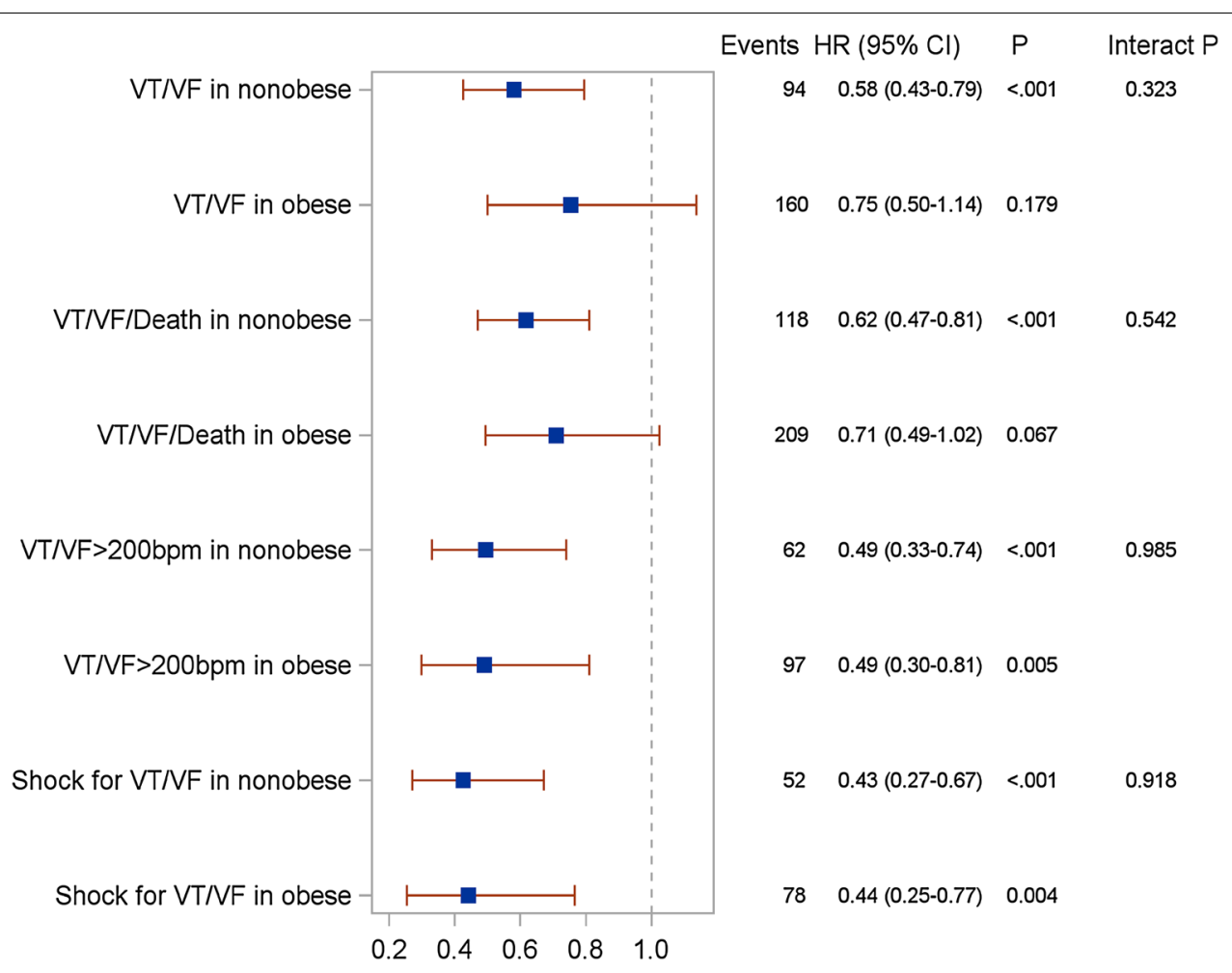

Fig. 3 The Effect of CRT-D vs. ICD in obese and non-obese patients on the risk of appropriate implantable cardioverter-defibrillator therapy. (VT/ VF-ventricular tachycardia/ventricular fibrillation)

by baseline conduction disturbances therefore our study included only patients with LBBB [21].

The mechanism of cardiac arrhythmias in obesity includes: heart remodeling including left ventricle hypertrophy, subclinical systolic impairment and diastolic dysfunction, pericardial adipose tissue inflammatory cytokine secretion and sympathetic over-activity [11]. Pathological myocardial changes such as myocyte hypertrophy, fibrosis, focal myocardial disarray, fatty infiltration and increased epicardial fat may contribute to increased risk of arrhythmias [7]. Despite the strong evidence that obesity may predispose to ventricular arrhythmias our current study did not support prior observations. In patients with obesity and heart failure, association between body mass index and subsequent cardiovascular risk is complex and known as "obesity paradox" [29,30], suggesting that role of obesity accompanied establish HF, the effect on clinical outcome including risk for VT/VF may be neutral or even positive at this stage of disease [31].

In summary, strategies to reduce risk for negative health outcomes in people with obesity should be implemented early before the development of HF. This is supported in our analysis because obese patients are 5 years younger than people without obesity. The preventive strategies may include adequate body weight monitoring which may translate into prevention of HF development and consecutive ICD or CRT therapy [19]. 


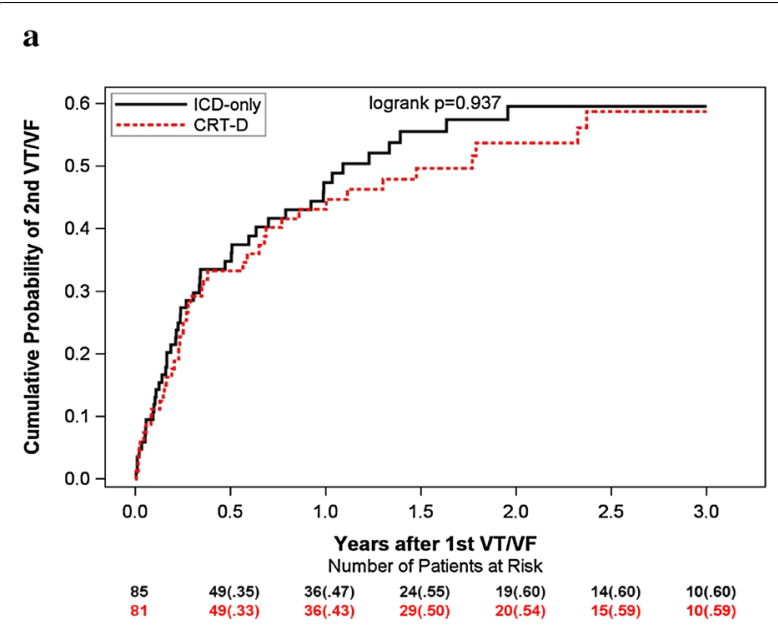

b

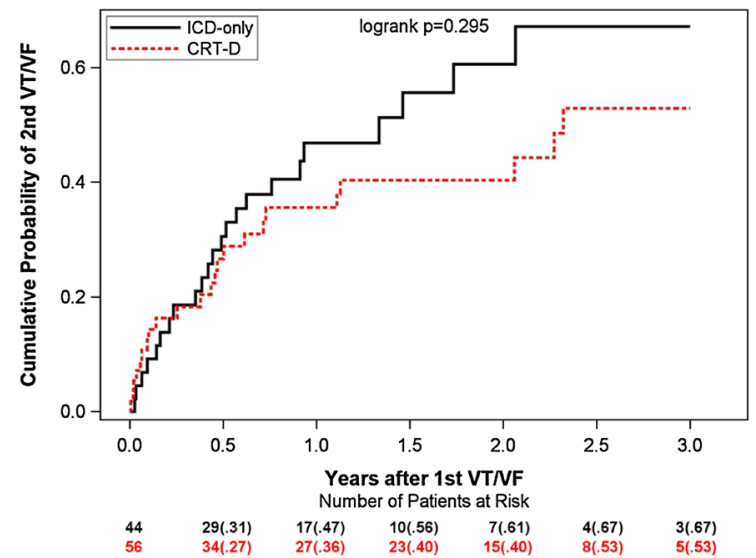

Fig. 4 Cumulative probability of VTNF following a first VT/NF event by treatment arm in: a non-obese and $\mathbf{b}$ obese patients

Limitation of our study relates to a retrospective and nonrandomized nature of this post hoc analysis. An adjusted multivariate analysis was performed, taking into account many confounders associated with analyzed end point and those that played a significant role on this outcome in our population.

In conclusion, our findings indicate that obesity in mild heart failure did not diminish clinical benefit of cardiac resynchronization therapy. Patients with obesity should
Table 4 The effect of CRT-D in obese and non-obese patients on the risk of subsequent appropriate ICD therapy or death

\begin{tabular}{|c|c|c|c|c|c|}
\hline & $\begin{array}{l}\text { Number } \\
\text { of events }\end{array}$ & $\begin{array}{l}\text { Non- } \\
\text { obese }\end{array}$ & $\begin{array}{l}\text { Number } \\
\text { of events }\end{array}$ & Obese & $p$ value \\
\hline & & $\begin{array}{l}\text { Adjusted HR } \\
(95 \% \mathrm{Cl}) \mathrm{p} \\
\text { value }\end{array}$ & & $\begin{array}{l}\text { Adjusted HR } \\
(95 \% \mathrm{Cl}) \mathrm{p} \\
\text { value }\end{array}$ & \\
\hline \multicolumn{6}{|c|}{ Subsequent VT/VF } \\
\hline VTNF & 371 & $\begin{array}{l}1.05 \\
(0.79-1.39) \\
0.748\end{array}$ & 272 & $\begin{array}{l}1.05 \\
(0.73-1.52) \\
0.797\end{array}$ & 0.508 \\
\hline $\begin{array}{l}\text { VTNF } \\
\text { greater } \\
\text { than } \\
200 \text { bpm }\end{array}$ & 85 & $\begin{array}{l}0.910 \\
(0.52-1.59) \\
0.741\end{array}$ & 68 & $\begin{array}{l}0.59 \\
(0.32-1.01) \\
0.086\end{array}$ & 0.243 \\
\hline $\begin{array}{l}\text { Shock } \\
\text { delivered } \\
\text { for VTNF }\end{array}$ & 82 & $\begin{array}{l}0.81 \\
(0.42-1.55) \\
0.522\end{array}$ & 55 & $\begin{array}{l}0.45 \\
(0.22-0.93) \\
0.031\end{array}$ & 0.135 \\
\hline \multicolumn{6}{|l|}{ Death } \\
\hline VTNF & 70 & $\begin{array}{l}2.02 \\
(1.14-3.57) \\
0.014\end{array}$ & 36 & $\begin{array}{l}2.79 \\
(1.37-5.68) \\
0.004\end{array}$ & 0.477 \\
\hline $\begin{array}{l}\text { VTNF } \\
\text { greater } \\
\text { than } \\
200 \text { bpm }\end{array}$ & 70 & $\begin{array}{l}2.58 \\
(1.33-4.98) \\
0.004\end{array}$ & 36 & $\begin{array}{l}2.39 \\
(1.07-5.38) \\
0.033\end{array}$ & 0.885 \\
\hline $\begin{array}{l}\text { Shock } \\
\text { delivered } \\
\text { for VTNF }\end{array}$ & 70 & $\begin{array}{l}3.15 \\
(1.6-6.2) \\
<0.001\end{array}$ & 36 & $\begin{array}{l}2.21 \\
(0.94-5.12) \\
0.064\end{array}$ & 0.514 \\
\hline
\end{tabular}

After adjustment for race (Black/African American), age at enrollment, creatinine $\geq 1.4$, female sex, left ventricle end diastolic volume index, myocardial infarction prior to enrollment, enrollment NYHA classification, prior hospitalization during prior year, $\mathrm{QRS}<150$, ventricular arrhythmias requiring treatment prior to enrolment

be offered CRT-D treatment and obesity should not preclude the use of CRT-D treatment when clinically indicated.

\section{Additional files}

Additional file 1: Table S1. The risk of appropriate implantable cardioverter-defibrillator therapy delivered for VTVF a full multivariable model.

Additional file 2: Figure S1. Association between appropriate ICD therapy delivered for VTNF and the BMI level. 


\section{Authors' contributions}

BSz designed study, analysed data and wrote the manuscript; BP performed statistical analysis, programming and contributed to study design; SS contributed to study design and discussion of the results; YB contributed to study design and discussion of the results; VK contributed to study design and discussion of the results; SM contributed to design of the Cox multivariable models; MK contributed to study design and discussion of the results; AJM is a principal investigator for the MADIT CRT study and help with critical revision; WZ participated in design and coordination and helped to draft the manuscript. All authors read and approved the final manuscript.

\section{Acknowledgements}

The MADIT-CRT study was supported by a research Grant from Boston Scientific to the University of Rochester, with funds distributed to the coordination and data center, enrolling centers, core laboratories, committees, and boards under subcontracts from the University of Rochester. Drs. Zareba and Moss have received Grant from Boston Scientific to conduct MADIT-CRT trial.

\section{Competing interests}

Drs. Wojciech Zareba and Arthur J. Moss are guarantors of this work and have full access to data and data analysis. The MADIT-CRT study was supported by a research Grant from Boston Scientific to the University of Rochester, with funds distributed to the coordination and data center, enrolling centers, core laboratories, committees, and boards under subcontracts from the University of Rochester.

Received: 15 April 2016 Accepted: 24 May 2016

Published online: 07 July 2016

\section{References}

1. Reaven GM. Relationships among insulin resistance, type 2 diabetes, essential hypertension, and cardiovascular disease: similarities and differences. J Clin Hypertension. 2011;13(4):238-43.

2. Manson JE, Colditz GA, Stampfer MJ, Willett WC, Rosner B, Monson RR, Speizer FE, Hennekens $\mathrm{CH}$. A prospective study of obesity and risk of coronary heart disease in women. N Eng J Med. 1990;322(13):882-9.

3. Messerli FH, Nunez BD, Ventura HO, Snyder DW. Overweight and sudden death. Increased ventricular ectopy in cardiopathy of obesity. Arch Intern Med. 1987;147(10):1725-8.

4. Kenchaiah S, Evans JC, Levy D, Wilson PW, Benjamin EJ, Larson MG, Kannel WB, Vasan RS. Obesity and the risk of heart failure. N Eng J Med. 2002;347(5):305-13.

5. Borlaug BA. The pathophysiology of heart failure with preserved ejection fraction. Nat Rev Cardiol. 2014;11(9):507-15.

6. Shah RV, Abbasi SA, Heydari B, Farhad H, Dodson JA, Bakker JP, John RM, Veves A, Malhotra A, Blankstein R, et al. Obesity and sleep apnea are independently associated with adverse left ventricular remodeling and clinical outcome in patients with atrial fibrillation and preserved ventricular function. Am Heart J. 2014;167(4):620-6.

7. Abel ED, Litwin SE, Sweeney G. Cardiac remodeling in obesity. Physiol Rev. 2008;88(2):389-419.

8. Aubin MC, Cardin S, Comtois P, Clement R, Gosselin H, Gillis MA, Le Quang K, Nattel S, Perrault LP, Calderone A. A high-fat diet increases risk of ventricular arrhythmia in female rats: enhanced arrhythmic risk in the absence of obesity or hyperlipidemia. J Appl Physiol. 2010;108(4):933-40.

9. Lalani AP, Kanna B, John J, Ferrick KJ, Huber MS, Shapiro LE. Abnormal signal-averaged electrocardiogram (SAECG) in obesity. Obesity Res. 2000;8(1):20-8

10. Narkiewicz K, Kato M, Pesek CA, Somers VK. Human obesity is characterized by a selective potentiation of central chemoreflex sensitivity. Hypertension. 1999;33(5):1153-8.

11. Pathak RK, Mahajan R, Lau DH, Sanders P. The implications of obesity for cardiac arrhythmia mechanisms and management. Can J Cardiol. 2015;31(2):203-10.

12. Magnani JW, Hylek EM, Apovian CM. Obesity begets atrial fibrillation: a contemporary summary. Circulation. 2013;128(4):401-5.
13. Hernandez AV, Kaw R, Pasupuleti V, Bina P, loannidis JP, Bueno H, Boersma E, Gillinov M. Cardiovascular meta-analyses research G: association between obesity and postoperative atrial fibrillation in patients undergoing cardiac operations: a systematic review and meta-analysis. Ann Thorac Surg. 2013;96(3):1104-16.

14. Munger TM, Dong YX, Masaki M, Oh JK, Mankad SV, Borlaug BA, Asirvatham SJ, Shen WK, Lee HC, Bielinski SJ, et al. Electrophysiological and hemodynamic characteristics associated with obesity in patients with atrial fibrillation. J Am Coll Cardiol. 2012;60(9):851-60.

15. Iwasaki YK, Shi Y, Benito B, Gillis MA, Mizuno K, Tardif JC, Nattel S. Determinants of atrial fibrillation in an animal model of obesity and acute obstructive sleep apnea. Heart Rhythm. 2012;9(9):1409-1416 e1401.

16. Wang TJ, Parise H, Levy D, D'Agostino RB Sr, Wolf PA, Vasan RS, Benjamin EJ. Obesity and the risk of new-onset atrial fibrillation. JAMA. 2004;292(20):2471-7.

17. Pietrasik G, Goldenberg I, McNitt S, Moss AJ, Zareba W. Obesity as a risk factor for sustained ventricular tachyarrhythmias in MADIT II patients. J Cardiovasc Electrophysiol. 2007:18(2):181-4.

18. Bharati S, Lev M. Cardiac conduction system involvement in sudden death of obese young people. Am Heart J. 1995;129(2):273-81.

19. Adabag S, Huxley RR, Lopez FL, Chen LY, Sotoodehnia N, Siscovick D, Deo R, Konety S, Alonso A, Folsom AR. Obesity related risk of sudden cardiac death in the atherosclerosis risk in communities study. Heart. 2015;101(3):215-21.

20. Moss AJ, Hall WJ, Cannom DS, Klein H, Brown MW, Daubert JP, Estes NA 3rd, Foster E, Greenberg H, Higgins SL, et al. Cardiac-resynchronization therapy for the prevention of heart-failure events. N Engl J Med. 2009;361(14):1329-38.

21. Zareba W, Klein H, Cygankiewicz I, Hall WJ, McNitt S, Brown M, Cannom D, Daubert JP, Eldar M, Gold MR, et al. Effectiveness of cardiac resynchronization therapy by QRS morphology in the multicenter automatic defibrillator implantation trial-cardiac resynchronization therapy (MADIT-CRT). Circulation. 2011:123(10):1061-72.

22. Kuczmarski RJ, Flegal KM. Criteria for definition of overweight in transition: background and recommendations for the United States. Am J Clin Nutr. 2000;72(5):1074-81.

23. Moss AJ, Brown MW, Cannom DS, Daubert JP, Estes M, Foster E, Greenberg HM, Hall WJ, Higgins SL, Klein H, et al. Multicenter automatic defibrillator implantation trial-cardiac resynchronization therapy (MADIT-CRT): design and clinical protocol. Ann Noninvasive Electrocardiol. 2005;10(4 Suppl):34-43.

24. Kutyifa V, Kloppe A, Zareba W, Solomon SD, McNitt S, Polonsky S, Barsheshet A, Merkely B, Lemke B, Nagy VK, et al. The influence of left ventricular ejection fraction on the effectiveness of cardiac resynchronization therapy: MADIT-CRT (multicenter automatic defibrillator implantation trial with cardiac resynchronization therapy). J Am Coll Cardiol. 2013;61(9):936-44

25. Braunwald $\mathrm{E}$. The war against heart failure: the Lancet lecture. Lancet. 2015:385(9970):812-24

26. Venkataraman G, Mathur D, Joshi S, Strickberger A. Comparison of ICD implantation in obese and nonobese patients. Pacing Clin Electrophysiol. 2014;37(4):481-5

27. Tang AS, Wells GA, Talajic M, Arnold MO, Sheldon R, Connolly S, Hohnloser SH, Nichol G, Birnie DH, Sapp JL, et al. Cardiac-resynchronization therapy for mild-to-moderate heart failure. N Engl J Med. 2010;363(25):2385-95.

28. Ouellet G, Huang DT, Moss AJ, Hall WJ, Barsheshet A, McNitt S, Klein H, Zareba W, Goldenberg I. Effect of cardiac resynchronization therapy on the risk of first and recurrent ventricular tachyarrhythmic events in MADIT-CRT. J Am Coll Cardiol. 2012;60(18):1809-16.

29. Aktas MK, Zareba W, Huang DT, McNitt S, Polonsky S, Chen L, Stockburger M, Merkely B, Moss AJ, Kutyifa V. The effect of weight loss on clinical outcomes in patients implanted with a cardiac resynchronization therapy device-A MADIT-CRT substudy. J Cardiac Fail. 2014;20(3):183-9.

30. De Schutter A, Lavie CJ, Patel DA, Milani RV. Obesity paradox and the heart: which indicator of obesity best describes this complex relationship? Curr Opinion Clin Nutr Metab Care. 2013;16(5):517-24.

31. Cai C, Hua W, Ding LG, Wang J, Chen KP, Yang XW, Liu ZM, Zhang S. Association of body mass index with cardiac reverse remodeling and long-term outcome in advanced heart failure patients with cardiac resynchronization therapy. Circ J. 2014;78(12):2899-907. 